\title{
Modulation of the Structure and Properties of Uranyl Ion Coordination Polymers Derived from 1,3,5-Benzenetriacetate by Incorporation of $\mathrm{Ag}(\mathrm{I})$ or $\mathrm{Pb}(\mathrm{II})$
}

\author{
Pierre Thuéry and Jack Harrowfield
}

\section{Crystal structure of $\left[\mathrm{Ag}_{2}(\mathrm{HBTA})\left(\mathrm{H}_{2} \mathrm{O}\right)\right]$}

$\mathrm{C}_{12} \mathrm{H}_{12} \mathrm{Ag}_{2} \mathrm{O}_{7}, M=483.96$, triclinic, space group $P \overline{1}, a=4.6923(3), b=11.6790(8), c=12.8383(9) \AA, \alpha=71.942(3), \beta=$ 85.521(4), $\gamma=84.483(4)^{\circ}, V=664.94(8) \AA^{3}, Z=2, D_{\mathrm{c}}=2.417 \mathrm{~g} \mathrm{~cm}^{-3}, \mu=2.976 \mathrm{~mm}^{-1}, F(000)=468$. Refinement of 190 parameters on 2530 independent reflections out of 32803 measured reflections $\left(R_{\text {int }}=0.084\right)$ led to $R_{1}=0.033, w R_{2}=0.077, S$ $=1.028, \Delta \rho_{\max }=0.92, \Delta \rho_{\min }=-1.16 \mathrm{e} \AA^{-3}$.

Figure S1. Top left: View of the complex $\left[\mathrm{Ag}_{2}(\mathrm{HBTA})\left(\mathrm{H}_{2} \mathrm{O}\right)\right]$. Displacement ellipsoids are drawn at the $50 \%$ probability level. Carbon-bound hydrogen atoms are omitted. Hydrogen bonds are shown as dashed lines. Symmetry codes: $\mathrm{i}=1-x, 2-$ $y,-z ; \mathrm{j}=2-x, 2-y,-z ; \mathrm{k}=1-x, 1-y,-z ; 1=x, y, z+1 ; \mathrm{m}=2-x, 1-y,-z$. Top right: View of the $2 \mathrm{D}$ assembly. Bottom left: Packing with layers viewed edge-on. Bottom right: Nodal representation of the 2D network viewed down the $\left[\begin{array}{lll}1 & 0 & -1\end{array}\right]$ axis. Dark blue: silver, red: oxygen, light blue: tricarboxylate ligand.
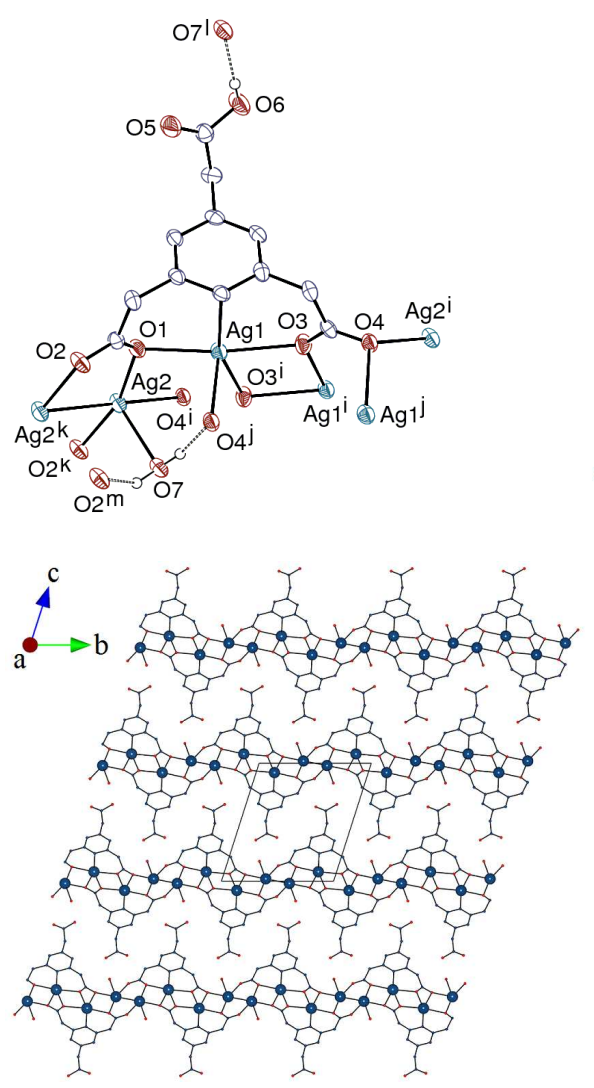
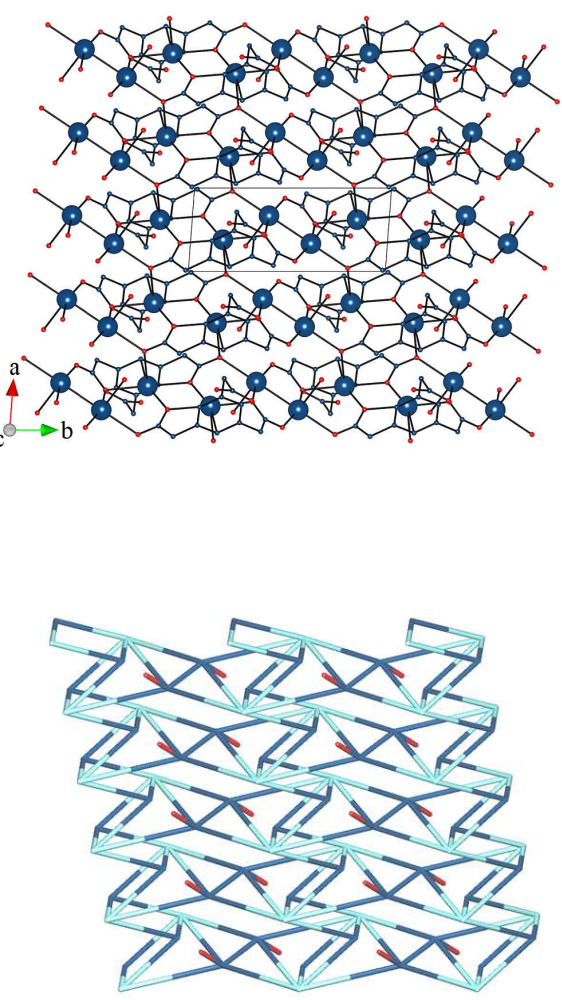